\title{
Implementasi Analog Front End Pada Sensor Kapasitif Untuk Pengaturan Kelembaban Menggunakan Mikrokontroller STM32
}

\author{
Rendy Setiawan, Muhammad Rivai, dan Suwito. \\ Jurusan Teknik Elektro, Fakultas Teknologi Industri, Institut Teknologi Sepuluh Nopember (ITS) \\ J1. Arief Rahman Hakim, Surabaya 60111 \\ E-mail: rendy.setiawan12@mhs.ee.its.ac.id,muhammad_rivai@ee.its.ac.id,masaji@ee.its.ac.id
}

\begin{abstract}
Abstrak-Sensor kapasitif merupakan jenis sensor yang mengubah stimulus fisik menjadi perubahan kapasitansi. Pada sensor kapasitif, adanya stray capacitance atau kapasitansi parasitik pada sensor dapat menyebabkan kesalahan dalam pengukuran. Dalam aplikasi pengaturan kelembaban, dibutuhkan sistem pengukuran kelembaban dengan kesalahan minimum untuk mendapatkan nilai setting point dengan galat minimum. Maka diperlukan implementasi analog front end yang dapat meminimalisir kesalahan akibat stray capacitance pada sensor kapasitif untuk pengukuran kelembaban relatif. Pada sistem pengukuran sensor kapasitif ini, sensor dieksitasi dengan sinyal AC yang dihasilkan oleh generator sinyal pada frekuensi 10 $\mathrm{KHz}$, kemudian diimplementasikan analog front end untuk mengondisikan sinyal dari sensor. Keluaran dari analog front end dikonversi menjadi sinyal DC menggunakan demodulator sinkron dan filter low pass lalu dikonversi menjadi data digital menggunakan ADC di mikrokontroller STM32. Hasil pengukuran yang didapatkan dengan implementasi analog front end kemudian kemudian gunakan untuk mengatur kelembaban pada sebuah plant growth chamber. Berdasarkan hasil dari pengujian, rangkaian analog front end dapat mengompensasi stray capacitance dengan kesalahan pembacaan nilai kapasitansi maksimal sebesar $4.2 \%$ pada kondisi stray capacitance sebesar 236,6pF, 174,3pF dan 115,7pF. Implementasi analog front end pada pengaturan kelembaban menghasilkan galat pada setting point maksimal sebesar $8.8 \%$ untuk nilai RH 75\% dan $33 \%$.
\end{abstract}

Kata Kunci-analog front end, sensor kapasitif, stray capacitance.

\section{PENDAHULUAN}

$\mathrm{S}_{\mathrm{sin}}^{\mathrm{e}}$ ensor kapasitif merupakan jenis sensor yang mengonversi stimulus fisik menjadi perubahan dalam besaran elektrik yaitu kapasitansi. Sensor kapasitif digunakan dalam berbagai aplikasi pengukuran, antara lain : perpindahan linear dan rotasional, tekanan, gaya, torsi, akselerasi, kelembaban relatif, temperatur, tingkat ketinggian fluida. Penggunaan sensor kapasitif dalam pengukuran memiliki kekurangan yaitu terjadinya kesalahan akibat stray capacitance. Stray capacitance atau kapasitansi parasitik adalah kapasitansi yang tidak diinginkan atau seringkali tidak dapat dihindari yang timbul pada komponen, maupun rangkaian elektronik. Pada sensor kapasitif, kapasitansi sensor $C_{x}$ yang berubah terhadap kuantitas yang diukur seringkali lebih kecil dibandingkan dengan stray capacitance-nya. Akibatnya, dihasilkan perubahan output yang kecil, relatif terhadap nilai $C_{x}$ tapi dengan offset yang besar akibat stray capacitance dan terjadi kesalahan pembacaan stimulus yang diukur.

Dalam aplikasi pengaturan kelembaban, salah satu contohnya pada sebuah plant growth chamber yang merupakan ruangan dengan lingkungan terkendali untuk eksperimen biologi tanaman, salah satu spesifikasi yang diinginkan adalah pengaturan kelembaban dengan setting point yang stabil, sehingga didapatkan faktor lingkungan yang terkendali sesuai dengan nilai yang diinginkan, untuk menghasilkan eksperimen yang dapat direproduksi dan valid. Kesalahan hasil pengukuran dapat mempengaruhi setting point dari kontroller dan mengakibatkan setting point yang bergeser sehingga pengaturan kelembaban menjadi tidak optimal. Oleh karena itu pada aplikasi tersebut diperlukan implementasi analog front end yang dapat meminimalisir kesalahan akibat stray capacitance. Penggunaan rangkaian jembatan kapasitansi dapat meminimalisir terjadinya kesalahan, akan tetapi memiliki keterbatasan dalam hal linearitas. IC capacitance-to-digital converter AD7747[1] memiliki fitur koreksi untuk stray capacitance akan tetapi rentang stray capacitance yang dapat dikoreksi terbatas. Rangkaian capacitance-to-frequency converter pada[2] tidak linier untuk nilai kapasitansi yang kecil sehingga diimplementasikan analog front end berdasarkan hasil penelitian pada[3] yang dapat mengompensasi stray capacitance dengan rentang yang dapat disesuaikan.

\section{TEORI PENUNJANG}

\section{A. Sensor Kapasitif}

Sebuah kapasitor terdiri dari dua pelat konduktor yang dipisahkan oleh sebuah dielektrik(padat, cair atau gas) atau hampa udara. Kapasitansi (C) adalah hubungan antara jumlah muatan $(\mathrm{Q})$ dan perbedaan tegangan (V) antara dua pelat konduktor pada kapasitor, $\mathrm{C} / \mathrm{Q}=\mathrm{V}$. Kapasitansi ini bergantung pada penyusunan geometris dari pelat konduktor dan material dielektrik diantaranya. Contoh, pada gambar 5, sebuah kapasitor yang terdiri dari $n$ pelat sejajar dengan luasan $A$, memiliki jarak $d$ diantara kedua pelat dan konstanta material dielektrik $\varepsilon_{r}$ memiliki kapasitansi : 


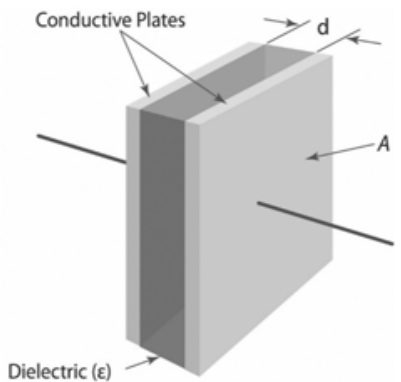

Gambar 1. Struktur fisik sebuah kapasistor pelat sejajar[4]

$$
C \approx \epsilon_{0} \epsilon_{r} \frac{A}{d}(n-1)
$$

$\varepsilon_{o}=$ konstanta dielektrik untuk ruang. maka stimulus atau fenomena fisik yang menghasilkan perubahan $\varepsilon_{r}, A$ atau $d$ akan menghasilkan perubahan nilai kapasitansi $C$ dan dapat dideteksi oleh kapasitor tersebut[4].

\section{B. Stray Capacitance}

Stray capacitance atau kapasitansi parasitik adalah kapasitansi yang tidak diinginkan atau seringkali tidak dapat dihindari yang timbul pada komponen, maupun rangkaian elektronik. Stray capacitance muncul apabila terdapat dua konduktor yang berdekatan satu sama lain, terlebih lagi apabila keduanya paralel satu sama lain, dan tidak di-short atau diselubungi dengan sebuah konduktor yang berfungsi sebagai Shield[5]. Pada sensor kapasitif, kapasitansi $C_{x}$ yang berubah terhadap kuantitas yang diukur seringkali lebih kecil dibandingkan dengan stray capacitance nya, terutama ketika sensor letaknya jauh dari rangkaian akuisisi data dan dihubungkan oleh kabel dengan panjang tertentu. Tiap kabel memiliki kapasitansi parasitik yang nilainya proporsional terhadap panjang kabel.

Kapasitansi parasitik ini mempengaruhi nilai kapasitansi sensor karena bertindak sebagai kapasitansi yang paralel terhadap kapasitansi sensor $C x$ sehingga kapasitansi total sensor menjadi $C_{x}+C_{s}$ dimana $C_{s}$ merupakan stray capacitance dari kabel. Akibat dari kapasitansi parasitik ini, keluaran dari sebuah rangkaian pengondisi sinyal untuk sebuah sensor kapasitif akan memiliki komponen $f\left(C_{x}\right)$ dan $f\left(C_{s}\right)$, akibat dari $C_{x}$ dan $C_{s}$ sehingga hasilkan perubahan keluaran yang kecil, relatif terhadap nilai $C_{x}$ tapi dengan offset yang besar pada keluaran, yang jelas tidak diinginkan[3].

\section{Analog Front End}

Analog front end merupakan rangkaian elektronika yang berperan dalam pengondisian sinyal dari sensor atau tranduser agar selanjutnya dapat diolah pada tahap berikutnya. Seb uah analog front end dapat meliputi rangkaian yang melakukan fungsi isolasi, penguatan, mixing, filtering dan fungsi - fungsi lain yang bertujuan untuk mengondisikan sinyal agar sesuai dengan kriteria tertentu.

Pada sensor kapasitif, adanya stray capacitance atau kapasitansi parasitik pada sensor dapat menyebabkan terjadinya kesalahan atau error dalam pengukuran yang menggunakan sensor kapasitif. Untuk mengatasi hal tersebut diimplementasikan analog front end berdasarkan hasil penelitian pada[3]. Gambar 2 Merupakan rangkaian analog front end yang diimplementasikan yang terdiri dari beberapa

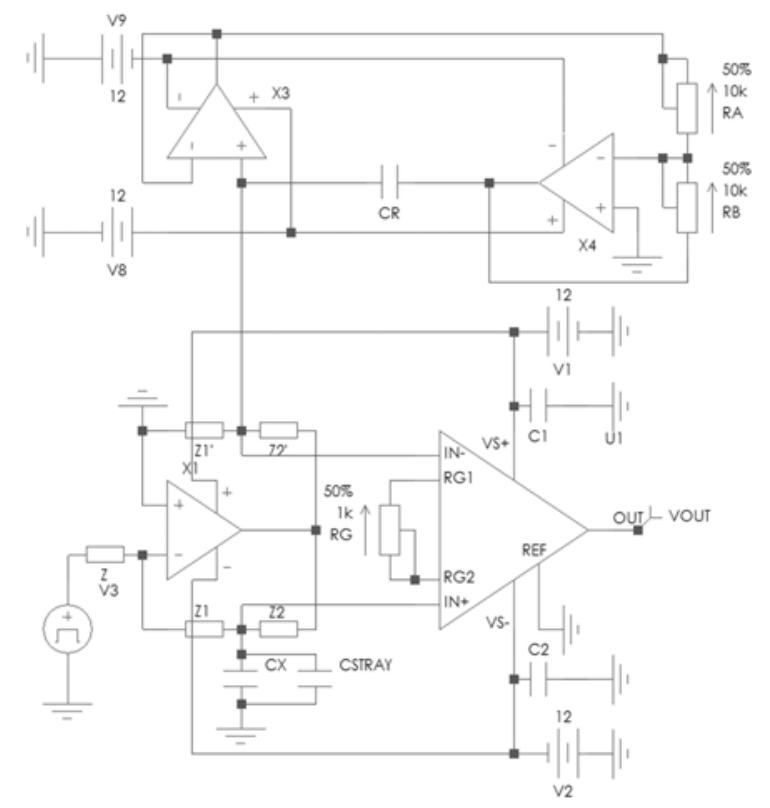

Gambar 2. Skematik analog front end [3]

bagian, yaitu penguat pembalik, pengali kapasitansi dan penguat instrumentasi.

\section{Generator Sinyal}

Penggunaan sinyal eksitasi untuk mengeksitasi sebuah sensor bergantung pada karakteristik turunan yang diukur dari sensor tersebut. Untuk mengukur impedansi yang perubahannya proposional terhadap perubahan kapasitansi sensor digunakan sinyal eksitasi AC. Sinyal AC digunakan karena impedansi merupakan respon frekuensi dari sensor kapasitif. Rangkaian generator sinyal AC terbagi menjadi dua kategori: generator sinyal sinusoidal, dan generator sinyal nonsinusoidal sedangkan generator sinyal nonsinusoidal sendiri meliputi generator pulsa, dan osilator relaksasi(relaxation oscillator). Generator sinyal yang digunakan pada penelitian ini adalah generator sinyal sinusoidal yang menggunakan IC ICL8038.

\section{E. Filter Low Pass}

Rangkaian resistor kapasitor, atau RC filter, adalah rangkaian elektronik yang terdiri atas resistor dan kapasitor yang menggunakan daya dari suatu sumber tegangan atau sumber arus. Rangkaian filter RC orde satu terdiri dari satu resistor dan satu kapasitor merupakan contoh sederhana dari rangkaian filter RC. Rangkaian filter RC merubah hubungan antara sinyal dengan frekuensi rendah maupun tinggi pada bagian masukan maupun keluaran untuk melewatkan sinyal yang diinginkan[6].

Frekuensi cut off( $\left.f_{c}\right)$ dari filter low pass orde satu dapat dituliskan dalam persamaan matematik sebagai berikut :

$$
f c=\frac{1}{2 \pi R C}
$$

Tegangan keluaran filter pasif low pass dapat dinyatakan dalam persamaan matematis sebagai berikut : 


$$
\text { Vout }=\frac{\frac{1}{j \omega c}}{\frac{1}{j \omega c}+R} \times \text { Vin }
$$

\section{F. Demodulator Sinkron}

Demodulator sinkron merupakan rangkaian elektronika yang berfungsi untuk melakukan konversi sinyal AC menjadi sinyal DC dengan amplitudo yang proporsional terhadap sinyal input.

Cara kerja demodulator dapat digambarkan pada gambar 3. Sebuah saklar analog yang dikendalikan oleh sinyal referensi digunakan untuk men-switch sebuah penguat operasional secara bergantian dari penguat tak pembalik ke penguat pembalik selama setengah siklus dari sinyal masukan, sehingga sinyal keluaran dari demodulator sinkron adalah sinyal hasil penyearahan gelombang penuh. Bentuk sinyal keluaran untuk setiap setengah siklus merupakan replika dari sinyal masukan, dengan polaritas yang dibalik, sesuai dengan hubungan fase antara sinyal referensi dan sinyal masukan.

\section{G. Mikrokontroller STM32}

Mikrokontroler STM32F4 discovery adalah mikrokontroler berbasis arsitektur ARM (Advanced Risc Machine) sebuah prosesor 32 bit yang lebih handal dalam hal transfer data dan hemat daya. Chip STM32F407V6GT6 mempunyai banyak fitur yang dapat digunakan, seperti $I / O$, Timer, ADC, dan DMA. Kecepatan clock-nya bisa mencapai $168 \mathrm{Mhz}$ sehingga memungkinkan untuk mengerjakan perintah program yang cukup panjang dalam waktu yang cukup singkat.

Fungsi dari mikrokontroller STM32 ini untuk mengkonversi data analog menjadi digital dengan memanfaatkan ADC internal yang memiliki resolusi maksimal 12 bit, mengirimkan data hasil konversi secara serial dan implementasi kontroller untuk sistem.

\section{H. Plant Growth Chamber}

Salah satu contoh aplikasi yang membutuhkan pengaturan kelembaban dengan setting point yang memiliki galat minimum adalah plant growth chamber. Sebuah plant growth chamber merupakan ruangan dengan lingkungan terkendali, yang krusial untuk mendapatkan hasil pengamatan yang dapat direproduksi dalam penelitian eksperimen biologi tanaman. Plant growth chamber memungkinkan peneliti untuk menentukan pengaruh dari parameter biotik atau abiotik tertentu pada tanaman. Dengan mengubah satu faktor atau lebih (misalnya : temperatur, kelembaban) maka pengaruhnya terhadap tanaman dapat diteliti. Plant growth chamber memungkinkan peneliti untuk menentukan kondisi lingkungan apa yang respon tertentu pada tanaman. Beberapa faktor lingkungan yang dapat dikendalikan pada sebuah plant growth chamber antara lain: intensitas cahaya, kelembaban, temperatur, aliran udara, kadar $\mathrm{CO}_{2}$ udara.

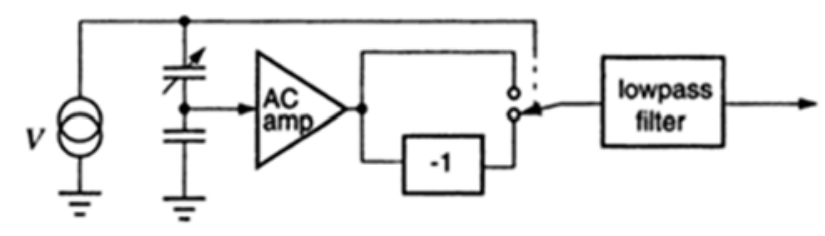

Gambar 3. Ilustrasi prinsip kerja rangkaian demodulator sinkron

\section{PERANCANGAN SISTEM}

\section{A. Diagram Blok Sistem}

Blok diagram sistem ini ditunjukkan pada gambar 4. Nilai referensi diatur secara program dimikrokontroller STM32. Kemudian mikrokontroller melakukan akuisisi data kelembaban relatif dari plant melalui sensor dan sistem akuisisi data. Data ini diolah untuk dijadikan hasil pengukuran kelembaban relatif, yang nilainya dikirim kembali ke komputer melalui komunikasi serial untuk ditampilkan, serta dibandingkan dengan nilai referensi untuk menghasilkan nilai galat. Nilai galat ini diproses oleh kontroller yang di implementasikan di mikrokontroller STM32. Sinyal kontrol yang sesuai kemudian dikirimkan ke aktuator untuk menghasilkan aksi kontrol pada plant.

\section{B. Rangkaian Generator Sinyal}

Rangkaian generator sinyal pada gambar 5 digunakan untuk menghasilkan sinyal eksitasi AC untuk sensor kapasitif. Untuk mendapatkan duty cycle sebesar $50 \%$, dipilih nilai $R_{1}=R_{2}$. Dengan menggunakan dua resistor pewaktuan terpisah, frekuensi sinyal keluaran dapat dinyatakan dalam persamaan :

$f=\frac{1}{t_{1}+t_{2}}=\frac{1}{\frac{R_{1} C}{0.66}\left(1+\frac{R_{2}}{2 R_{1}-R_{2}}\right)}$

Atau jika $\mathrm{R}_{1}=\mathrm{R}_{2}=\mathrm{R}$

$f=\frac{0.33}{R C}$

Dengan C merupakan kapasitor pewaktuan eksternal. Performa optimum didapatkan ketika arus charging berada pada rentang $10 \mu \mathrm{A}$ sampai $1 \mathrm{~mA}$. Besar arus charging dapat dihitung dari persamaan berikut :

$I=\frac{R_{1} \times\left(V_{+}-V_{-}\right)}{\left(R_{1}+R_{2}\right)} \times \frac{1}{R_{1}}=\frac{0.22\left(V_{+}-V_{-}\right)}{R 1}$

Dari persamaan 7, dipilih $\mathrm{R}_{1}=\mathrm{R}_{2}=33 \mathrm{~K} \Omega$ dengan arus $\mathrm{I}=$ $160 \mu \mathrm{A}$. Untuk mendapatkan frekuensi sinyal keluaran $10 \mathrm{KHz}$ maka :

$C 1=\frac{10 K H z}{0.33 \times 33 K \Omega}$

Dipilih nilai C1 sebesar 100nF.

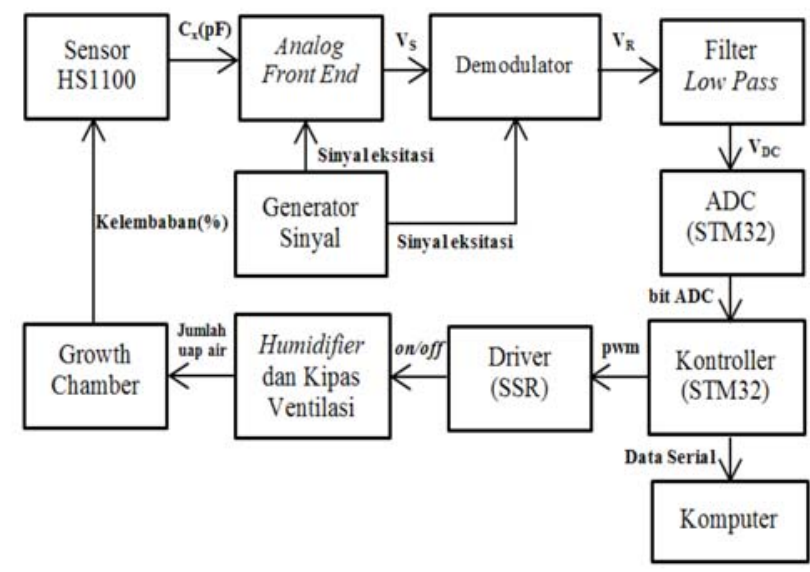

Gambar 4. Blok Diagram Sistem yang Dirancang 


\section{Filter Low Pass}

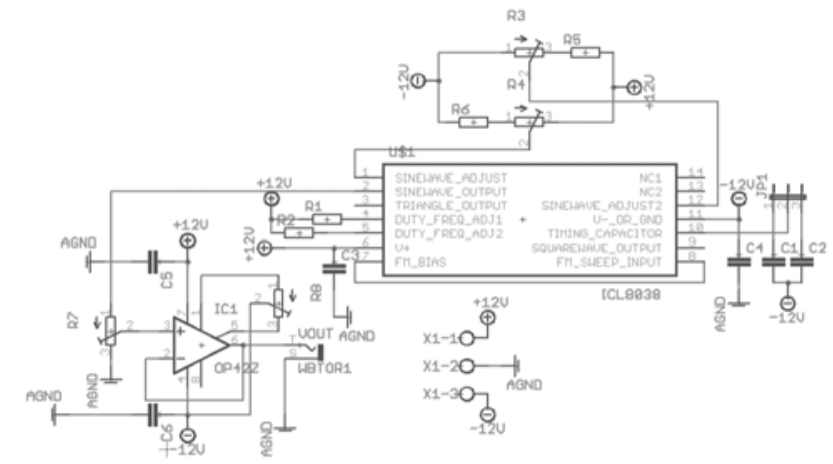

Gambar 5. Rangkaian Generator Sinyal

Filter low pass pada gambar 6 berfungsi untuk merata rata(averaging) keluaran rangkaian demodulator sinkron yang berupa sinyal hasil penyearahan gelombang penuh menjadi sinyal DC dan mereduksi frekuensi sinyal eksitasi $10 \mathrm{KHz}$ dari sensor. Dalam rancangan ini dipilih filter low pass $-40 \mathrm{~dB}$ dengan frekuensi cut-off sebesar $2.5 \mathrm{~Hz}$. Frekuensi cut-off ini dipilih untuk mendapatkan respon DC dari keluaran demodulator sinkron. Untuk mendapatkan frekuensi cut-off sebesar $2.5 \mathrm{~Hz}$, dipilih $\mathrm{R}_{1}$ dan $\mathrm{R}_{2}$ sebesar $82 \mathrm{~K} \Omega$ dan $150 \mathrm{~K} \Omega$. Nilai ini dipilih berdasarkan pertimbangan agar nilai kapasitor yang digunakan tidak terlalu besar. Dengan nilai resistor $\mathrm{R}_{1}$ dan $\mathrm{R}_{2}$ sebesar $82 \mathrm{~K} \Omega$ dan $150 \mathrm{~K} \Omega$, nilai $\mathrm{C}_{1}$ dan $\mathrm{C}_{2}$ dipilih $470 \mathrm{nF}$ dan $680 \mathrm{nF}$.

\section{Demodulator Sinkron}

Pada penelitian ini, digunakan rangkaian demodulator sinkron seperti pada gambar 7 yang menggunakan IC AD630 produksi Analog Devices. Sinyal keluaran analog front end dihubungkan ke pin RINB dan RA, sedangkan sinyal eksitasi sensor dihubungkan ke pin SELB. Input komparator B(SELB) dihubungkan ke referensi ground, sehingga ketika sinyal eksitasi sensor polaritasnya positif, komparator internal IC mengaktifkan masukan A dan AD630 berfungsi sebagai penguat tak pembalik dengan penguatan 1 , dan saat sinyal eksitasi sensor polaritasnya negatif, komparator mengaktifkan masukan B dan AD630 berfungsi sebagai penguat pembalik dengan gain 1. Pin 12 dari IC AD630 merupakan pin keluaran dan dihubungkan ke pin 12(COMP) untuk menghubungkan kapasitor kompensasi frekuensi internal dalam IC. Alasan penggunaan kapasitor kompensasi frekuensi ini adalah untuk mengoptimalkan bandwidth dari IC AD630.

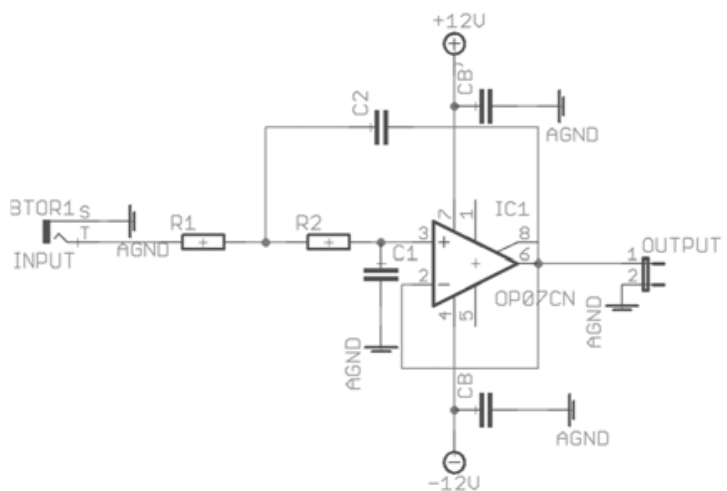

Gambar 6. Rangkaian Filter Low Pass

\section{E. Analog Front End}

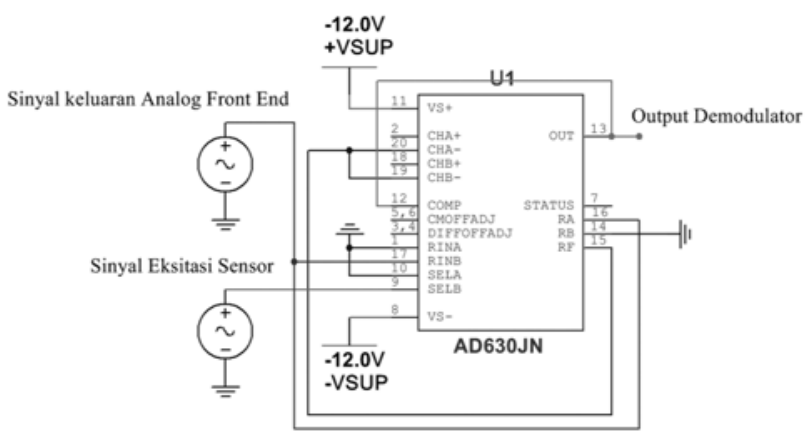

Gambar 7. Rangkaian Demodulator Sinkron

Pada bagian T network penguat pembalik di gambar $8, Z_{1}$ dan $Z_{2}$ serta nilai $Z_{1}{ }^{\mathrm{I}}$ dan $Z_{2}{ }^{\mathrm{I}}$ pada bagian kompensator diimplementasikan menggunakan resistor, dengan nilai $R_{1}=Z_{1}$ $=\mathrm{Z}_{1}{ }^{\mathrm{I}}$ sebesar $1 \mathrm{M} \Omega$ dan $\mathrm{R}_{2}=\mathrm{Z}_{2}=\mathrm{Z}_{2}{ }^{\mathrm{I}}$ sebesar $180 \Omega$. Nilai ini dipilih untuk mendapatkan kondisi dimana $\left[1>>1+R_{P}\right.$. $J \omega C_{R}$ ] sehingga pengaruh stray capacitance pada keluaran dapat dikompensasi selama nilai $\mathrm{C}_{\mathrm{R}}=\mathrm{C}_{\mathrm{S}}$ (stray capacitance). Nilai $Z$ dipilih sebesar $100 \mathrm{~K} \Omega$ untuk menghindari penguatan sinyal input yang terlalu besar pada node $\mathrm{V}_{\mathrm{X}}$

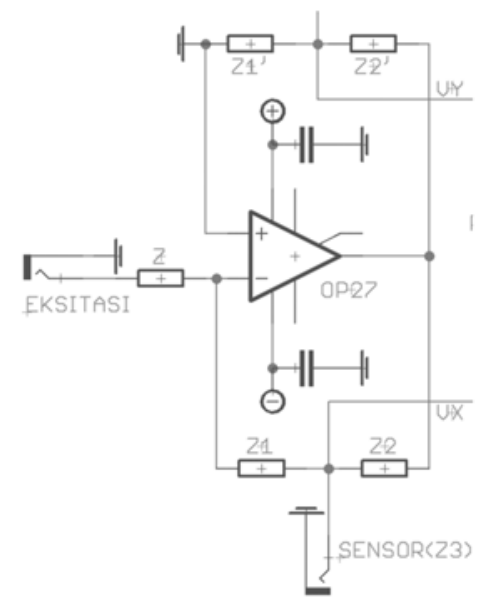

Gambar 8. Skematik rangkaian penguat pembalik pada analog front end

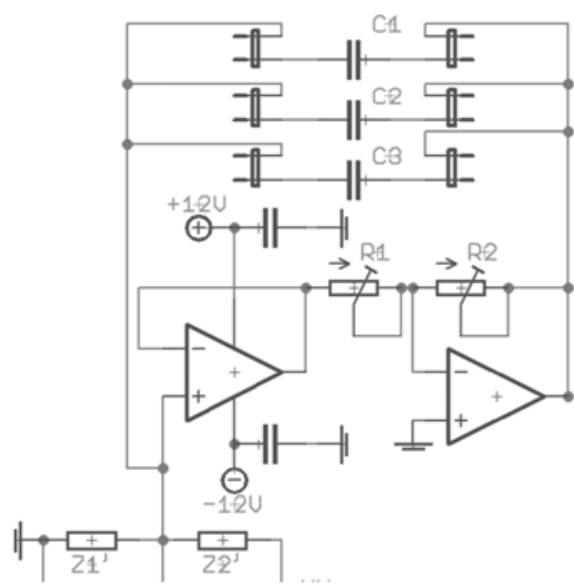

Gambar 9. Skematik Rangkaian Pengali Kapasitansi 
Pada rangkaian pengali kapasitansi di gambar 9, digunakan kapasitor referensi $\mathrm{C}_{\mathrm{R}}$ dengan 3 nilai yang berbeda $(\mathrm{C} 1, \mathrm{C} 2, \mathrm{C} 3)$ untuk mengakomodasi rentang kapasitansi stray yang dikompensasi. Kapasitor referensi ini nilainya diukur menggunakan LCR Meter BK Precision 8898 dengan nilai terukur $149,7 \mathrm{pF}(\mathrm{C} 1), 99,5 \mathrm{pF}(\mathrm{C} 2)$ dan $220 \mathrm{pF}(\mathrm{C} 3)$. Resistor R1 dan $\mathrm{R} 2$ diimplementasikan menggunakan resistor multiturn dengan nilai $1 \mathrm{~K} \Omega$.

Pada bagian penguat instrumentasi, digunakan IC AD620 yang merupakan IC penguat instrumentasi produksi Analog Devices. Resistor internal pada AD620 nilainya tetap, sebesar $24,7 \mathrm{k} \Omega$, sehingga penguatan dapat dihitung berdasarkan nilai tahanan eksternal RG dengan persamaan (9).

$$
G=\frac{49.4 k \Omega}{R G}+1
$$

\section{F. Plant Growth Chamber}

Pada tugas akhir ini dirancang sebuah plant growth chamber sederhana dengan dimensi $40 \mathrm{~cm} \times 40 \mathrm{~cm} \times 40 \mathrm{~cm}$. Plant growth chamber ini digunakan sebagai aplikasi pengaturan kelembaban, dan memverifikasi hasil pengukuran sensor kapasitif dengan menggunakan analog front end. Kriteria yang harus dimiliki dari plant growth chamber yang didesain antara lain : ruangan tertutup dengan insulasi yang baik, dan kelembaban yang dapat diatur/dikendalikan. Gambar tiga dimensi desain pada gambar 10 dibuat menggunakan perangkat lunak Sketch-up.

\section{HASIL PENGUJIAN}

\section{A. Realisasi Plant Growth Chamber}

Plant growth chamber yang direalisasikan pada tugas akhir ini memiliki bentuk kubus dengan dimensi panjang $40 \mathrm{~cm}$, lebar $40 \mathrm{~cm}$ dan tinggi $40 \mathrm{~cm}$. Konstruksi chamber terbuat dari bahan MDF(Medium density fibreboard). Alasan penggunaan bahan ini adalah mudah dimanipulasi, kokoh dan harganya relatif lebih murah untuk dimensi bahan yang luas dibandingkan dengan bahan lain, misalnya akrilik atau mika. Pada bagian depan dibuat lubang untuk akses ke bagian dalam chamber dengan ukuran $20 \mathrm{~cm} \times 20 \mathrm{~cm}$. Bagian dalam chamber dilapisi dengan alumunium foil untuk menjaga suhu udara didalam ruangan agar stabil dan tidak terlalu banyak dipengaruhi oleh suhu udara dilingkungan sekitar chamber.

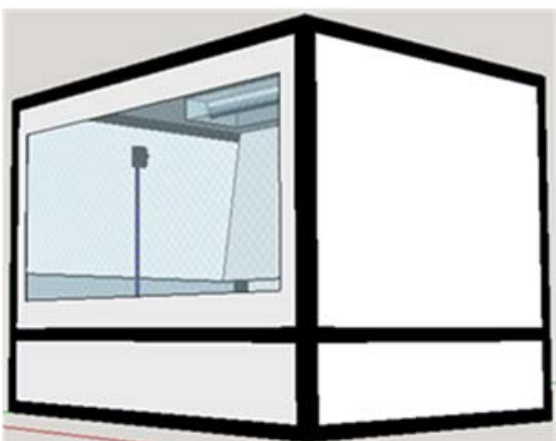

Gambar 10. Visualisasi 3D tampak depan plant growth chamber.

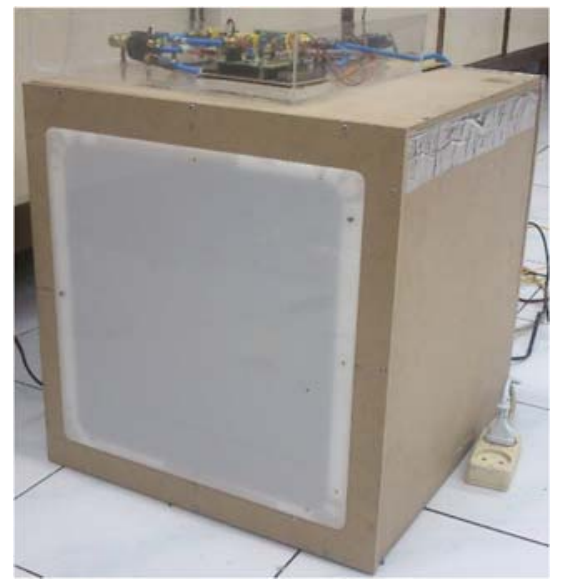

Gambar 11. Realisasi plant growth chamber(tampak depan)

\section{B. Pengujian Kompensasi Stray Capacitance}

Pengujian ini dilakukan untuk mengetahui performa analog front end dalam mengkompensasi stray capacitance. Pengujian dilakukan dengan memvariasikan kapasitansi dari sensor yang berupa 6 buah kapasitor yang nilainya sudah diukur sebelumnya menggunakan LCR Meter BK Precision 8089B. Sensor dihubungkan menggunakan kabel audio Canare L2T2S sepanjang 2 Meter, 1.5 Meter dan 1 Meter dengan stray capacitance terukur LCR masing - masing sebesar $236,6 \mathrm{pF}$; $174,3 \mathrm{pF}$ dan $115,7 \mathrm{pF}$. Dari hasil pengujian ini didapatkan nilai kesalahan pembacaan maksimal terhadap nilai nominal yang terukur LCR meter pada kondisi stray capacitance $=236,6 \mathrm{pF}$ sebesar $0,209 \mathrm{pF}$ dan nilai kesalahan maksimal pada kondisi stray capacitance $=174,3 \mathrm{pF}$ sebesar $0,207 \mathrm{pF}$ dan nilai kesalahan pembacaan maksmial pada kondisi stray capacitance $=115,7 \mathrm{pF}$ sebesar $0,5694 \mathrm{pF}$.

\section{Pengujian Pengukuran Sensor Kapasitif Tanpa Analog Front End}

Pengujian ini dilakukan dengan melakukan pembacaan sensor kapasitif tanpa implementasi analog front end.

\begin{tabular}{|c|c|c|}
\hline $\begin{array}{c}\text { Cx } \\
\text { Teruku } \\
\text { r } \\
\text { LCR(p } \\
\text { F) } \\
\end{array}$ & Dengan Front End(pF) & Gal \\
\hline 10,2 & 9,8 & 4,2 \\
\hline 15,3 & 15,9 & 3,7 \\
\hline 20,2 & 20,2 & 0,1 \\
\hline 25,4 & 25,4 & 0,2 \\
\hline 33,4 & 33,3 & 0,4 \\
\hline 38,5 & 38,5 & 0,0 \\
\hline $\begin{array}{c}\mathbf{C x} \\
\text { Teruku } \\
\mathbf{r} \\
\text { LCR(p } \\
\text { F) } \\
\end{array}$ & Tanpa Front End(pF) & Gal \\
\hline
\end{tabular}




\begin{tabular}{ccc}
\hline 10,2 & 0,7 & 93,1 \\
15,3 & 0,8 & 94,8 \\
20,2 & 0,8 & 96,0 \\
25,4 & 0,8 & 96,9 \\
33,4 & 0,9 & 97,3 \\
38,5 & 0,9 & 97,7 \\
\hline \hline
\end{tabular}

Tabel 5. Perbandingan hasil pengukuran untuk stray capacitance $=174,3 \mathrm{pF}$

\begin{tabular}{ccc}
\hline \hline $\begin{array}{c}\text { Cx Terukur } \\
\text { LCR(pF) }\end{array}$ & Dengan Front End(pF) & Galat \\
\hline 10,2 & 10,1 & $1,1 \%$ \\
15,3 & 15,2 & $0,3 \%$ \\
20,2 & 20,4 & $1,0 \%$ \\
25,4 & 25,6 & $0,7 \%$ \\
33,4 & 33,3 & $0,3 \%$ \\
38,5 & 38,5 & $0,1 \%$ \\
\hline Cx Terukur & Tanpa Front End(pF) & Galat \\
LCR(pF) & 1,0 & $90,2 \%$ \\
\hline 10,2 & 1,0 & $93,5 \%$ \\
15,3 & 1,1 & $94,6 \%$ \\
20,2 & 1,1 & $95,7 \%$ \\
25,4 & 1,1 & $96,7 \%$ \\
33,4 & 1,1 & $97,1 \%$ \\
38,5 & &
\end{tabular}

Pengujian ini dilakukan dengan melakukan pembacaan sensor kapasitif tanpa implementasi analog front end. Pengujian dilakukan untuk membandingkan hasil pembacaan sensor kapasitif dengan implementasi analog front end dengan hasil pembacaan tanpa analog front end, serta memvalidasi kemampuan analog front end untuk mengkompensasi stray capacitance pada sensor. Tabel 4, tabel 5 dan tabel 6 merupakan perbandingan hasil pengukuran kapasitansi dengan penggunaan analog front end dan tanpa menggunakan analog front end. Hasil perbandingan menunjukkan bahwa pengukuran kapasitansi dengan menggunakan Analog Front End memiliki ketelitian yang lebih baik, untuk nilai stray capacitance yang sama, dengan kesalahan maksimum 4,2\% dibandingkan dengan pengukuran kapasitansi tanpa menggunakan Analog Front End yang memiliki kesalahan maksimum $97,7 \%$.

\begin{tabular}{ccc}
\begin{tabular}{c} 
Tabel 6. Perbandingan hasil pengukuran untuk stray capacitance $=236,6$ \\
\hline \hline $\begin{array}{c}\text { Cx Terukur } \\
\text { LCR(pF) }\end{array}$
\end{tabular} & Dengan Front End(pF) & Galat \\
\hline 10,2 & 10,1 & $1,1 \%$ \\
15,3 & 15,2 & $0,3 \%$ \\
20,2 & 20,4 & $1,0 \%$ \\
25,4 & 25,6 & $0,8 \%$ \\
33,4 & 33,3 & $0,3 \%$ \\
38,5 & 38,5 & $0,1 \%$ \\
\hline Cx Terukur & Tanpa Front End(pF) & Galat \\
\hline LCR(pF) & 1,4 & $86,3 \%$ \\
\hline 10,2 & 1,4 & $90,8 \%$ \\
\hline 15,3 & &
\end{tabular}

\begin{tabular}{lll}
\hline \hline 20,2 & 1,4 & $93,1 \%$ \\
25,4 & 1,4 & $94,5 \%$ \\
33,4 & 1,4 & $95,8 \%$ \\
38,5 & 1,4 & $96,4 \%$ \\
\hline \hline
\end{tabular}

\section{Pengujian Sistem Pengaturan Kelembaban Relatif}

Pengujian ini dilakukan untuk mengetahui pengaruh implementasi analog front end untuk pada sistem pengaturan kelembaban relatif. Gambar 11 merupakan realisasi plant growth chamber. Pada pengujian ini, digunakan dua nilai referensi kelembaban, yaitu $75 \%$ dan $33 \%$. Hasil pengujian untuk nilai kelembaban referensi $75 \%$ didapatkan nilai kelembaban yang tercapai terukur pada sensor DHT22 sebesar $76 \%$ sedangkan pada sensor HS1101 didapatkan nilai kelembaban terukur sebesar $78 \%$. Dari pengujian ini didapatkan galat respon kelembaban relatif sebesar 2,63\% terhadap hasil pembacaan sensor DHT22.

Hasil pengujian untuk nilai kelembaban referensi 33\% didapatkan nilai kelembaban yang tercapai, terukur pada sensor DHT22 sebesar 34\% sedangkan pada sensor HS1101 didapatkan nilai kelembaban terukur sebesar 37\%. Dari pengujian ini didapatkan galat respon kelembaban relatif sebesar $8.8 \%$ relatif terhadap hasil pembacaan sensor DHT22.

\section{KESIMPULAN}

Telah dirancang sistem pengukuran sensor kapasitif yang mengimplementasikan analog front end untuk mengompensasi stray capacitance pada sensor untuk aplikasi pengukuran kelembaban. Pada penelitian ini digunakan sebuah plant growth chamber. Berdasarkan data yang diperoleh, analog front end yang diimplementasikan dapat mengkompensasi stray capacitance pada sensor dengan kesalahan pembacaan nilai kapasitansi maksimal sebesar 0,5694 $\mathrm{pF}$ dengan gangguan stray capacitance sebesar 236,6pF, 174,3pF dan $115,7 \mathrm{pF}$. Perbandingan hasil pengukuran kapasitansi menunjukkan bahwa pengukuran dengan analog front end memiliki ketelitian yang lebih baik dengan kesalahan maksimum sebesar $4.2 \%$ dibandingkan dengan pengukuran tanpa analog front end yang memiliki kesalahan maksimum sebesar 97,7\%. Hasil implementasi analog front end pada pengaturan kelembaban menghasilkan galat maksimum pada setting point sebesar $8.8 \%$ untuk nilai set point sebesar $75 \%$ dan $33 \%$.

\section{DAFTAR PUSTAKA}

[1] Analog Devices, "24-bit capacitance-to-digital converter with temperature sensor," AD7747 datasheet.

[2] Q. Jia, G. Meijer, X. Li, dan C. Guan, "An integrated interface for grounded capacitive sensors," in Sensors, 2012 IEEE, Oct. 30-Nov. 03 2012, pp. 1076-1079.

[3] K, Cyril Baby, B, George, "A Simple Analog Front-End Circuit for Grounded Capacitive Sensors with Offset Capacitance," in Instrumentation and Measurement Technology Conference (I2MTC), 2013 CIEEE.

[4] Gulhane A., "Inductive Versus Capacitive Position Sensor," http:// www.robolab.in/inductive-versus-capacitive-position sensors/.html(diakses 8 Mei 2016)

[5] Guinta S., "Ask The Application Engineer - 21," http://www.analog.com/library/analogDialogue/Anniversary/21.html(dia kses 10 Mei 2016) 
[6] C. Sriprachuabwong, C. Srichan, T. Lomas dan A. Tuantranont,"Simple RC Low Pass Filter Circuit Fabricated by Unmodified Desktop Inkjet Printer," in International Conference on Electrical Engineering/Electronics Computer Telecommunications and Information Technology (ECTI-CON), 2010CIEEE. 